\title{
Two Cases of Hallopeau Type of Pemphigus Vegetans in Two Women in Burkina Faso
}

\author{
Jean-Baptiste Andonaba1 ${ }^{*}$, Issouf Konaté1, Konségré Valentin', Boukary Diallo1, \\ Muriel S Ouédraogo ${ }^{2}$, Nina Néssiné Korsaga-Somé2 \\ ${ }^{1}$ Université Nazi Boni de Bobo-Dioulasso, Bobo-Dioulasso, Burkina Faso \\ ${ }^{2}$ Université Ki-Zerbo de Ouagadougou, Ouagadougou, Burkina Faso \\ Email: ‘jb_andonaba@yahoo.fr,kletio@yahoo.fr, vallentin8konsegre@gmail.com,bkrdiallo@yahoo.fr, \\ sidnomam@yahoo.fr,nessine2000@yahoo.fr
}

How to cite this paper: Andonaba, J.-B., Konaté, I., Valentin, K., Diallo, B., Ouédraogo, M.S. and Korsaga-Somé, N.N. (2017) Two Cases of Hallopeau Type of Pemphigus Vegetans in Two Women in Burkina Faso. Journal of Cosmetics, Dermatological Sciences and Applications, 7, 199-203.

https://doi.org/10.4236/jcdsa.2017.73018

Received: June 16, 2017

Accepted: August 4, 2017

Published: August 7, 2017

Copyright ( 92017 by authors and Scientific Research Publishing Inc. This work is licensed under the Creative Commons Attribution International License (CC BY 4.0).

http://creativecommons.org/licenses/by/4.0/ (c) (i) Open Access

\begin{abstract}
Pemphigus of Hallopeau (PH) is a mild and pustular form of pemphigus vegetans, termed initially as "pyodermite végétante" described by Hallopeau. We report cases in two black women. Two women aged 32 and 36 respectively (case 1 and case 2) were seen for a pustulosis associated with blisters and erosions. Their history and their review have found the mouth ulcerations. The clinical examination showed pustules on the cephalic end, the trunk, the limbs and the large folds. Lesions had a polycyclic aspect and spread in a centrifugal way, developing towards budding, squamous and scabby erosions quickly surrounded by new pustules. Regression left a pigmented macula. Histological examination of the skin lesion showed images similar to vulgaris pemphigus (PV), together with hyperacanthosis and papillomatosis. Aspects observed in immunofluorescence were identical to those of PV (case1). General corticoid therapy led to a rapid disappearance of lesions in Case 1 but in Case 2 the Lever protocol combining corticoid and methotrexate have been used. PH is rarely described in our regions. Clinical diagnosis is not obvious for the uninitiated. Beyond the clinical presentation, $\mathrm{PH}$ has the same paraclinical diagnosis and the same treatment as PV.
\end{abstract}

\section{Keywords}

Pemphigus Vegetans, Hallopeau, Black Women, Burkina Faso

\section{Introduction}

Pemphigus of Hallopeau ( $\mathrm{PH})$ is a mild and postular form of pemphigus vegetans. It is also called Hallopeau type by Anglo-Saxons = Acrodermatitis continua suppurativa [1]. This affection termed "pyodermite végétante" was first de- 
scribed by Hallopeau in Paris at the 1st International Congress of Dermatology and syphiligraphy [2]. PH is a rare form of pemphigus vegetans and it has a better prognosis with $1 \%$ to $2 \%$ of spontaneous remission [3]. It is also considered as an infectious disease [4] or as a disease associated with inflammatory enterocolitis [5]. It is a rare affection that occurs in the form of vegetating and pustular lesions at the level of the main folds, accompanied by mouth ulcerations. Two cases are reported in black women to describe the clinical characteristics and therapeutic similarities of a quite rare affection.

\section{Case Synopsis}

\subsection{Case 1}

Ms MF, 32 years old, a primary school teacher was seen for pustules and blisters, accompanied by skin erosions. Her past medical history revealed mouth and tongue ulcerations five followed by repetitive pustulo-bullous eruptions of the scalp and armpits. Then, the condition worsened with many pustules spreading rapidly on an altered state of health. The examination revealed pustules due to inflammation on the the cephalic end, the trunk, the limbs and the large folds. Lesions had a polycyclic aspect, spread in a centrifugal way and developed towards budding, squamous and scabby erosions, surrounded quickly by new pustules (Figure 1(a)). Regression left a pigmented macula. The histopathological examination showed a suprabasal intraepidermic cleavage as in pemphigus vulgaris (PV), and specific lesions: hyperacanthosis and papillomatosis (Figure 2 ), with club-form bulge of interpapillary buds in the upper dermis. Immunofluorescence showed images evoking a PV. The general corticoid treatment (prednisone $60 \mathrm{mg} /$ day + usual care) associated with local care (Bath with $\mathrm{KMnO}_{4}+\mathrm{AQ}$ eosin 2\%) led to the disappearance of lesions within 10 days, leaving pigmented macula-type aftereffects (Figure 1(b)).

\subsection{Case 2}

$\mathrm{GH}$, a 36-year-old trader was seen for erosive lesions evolving for two months. Past medical history found a similar episode whose regression left a pigmented macula. On the onset, tongue and mouth ulcerations were reported, followed a
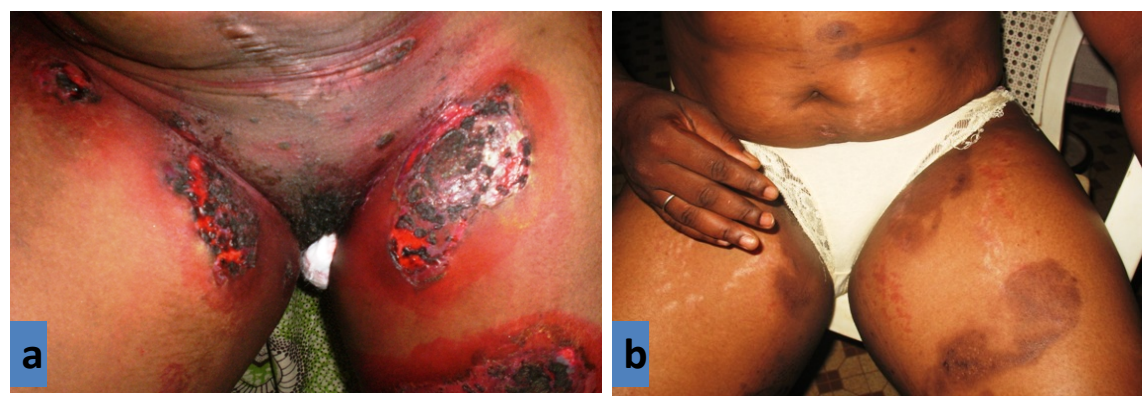

Figure 1. (a) Erosive lesions spreading in a centrifugal way and red coloring due to local treatment with eosin before admission to hospital. (b) Pigmented macular scar of lesions shown in Figure 1 after 15 days of general corticoid therapy. 
few weeks later by the spontaneous appearance of flabby pustular and bullous lesions, first on the face, arms, neck and trunk. The development was pointed out by the burst of some bubbles and pustules, causing large and crustous skin erosions (Figure 3(a)) and the outbreak of new lesions reaching lower limbs and the face, quickly surrounded by new pustules. The regression of lesions left aftereffect pigmentation. Erosive lesions were also reported on the tongue. Histology revealed images identical to Case 1 with light papillomatosis (Figure 4) and the immunofluorescence was not carried out for lack of financial means. The general corticoid therapy was associated with local care. After two (2) weeks of standing development or even spreading of lesions, we decided to use the Lever protocol (Corticosteroid + Methotrexate), which led to the disappearance of lesions within three (3) months (Figure 3(b)).

\section{Case Discussion}

Our two cases involve young negroid women in their thirties with a past medical history of similar episodes; These are cases of first recurrence. Very few cases of $\mathrm{PH}$ are described in french literature. Its prevalence is not well established. A

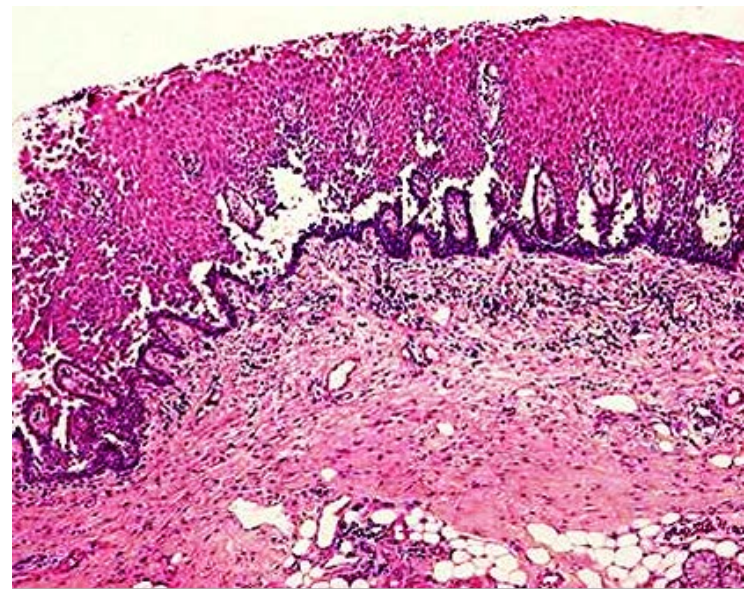

Figure 2. Suprabassl acantholysis with acantholytic cells, hyperacanthosis and papillomatosis.
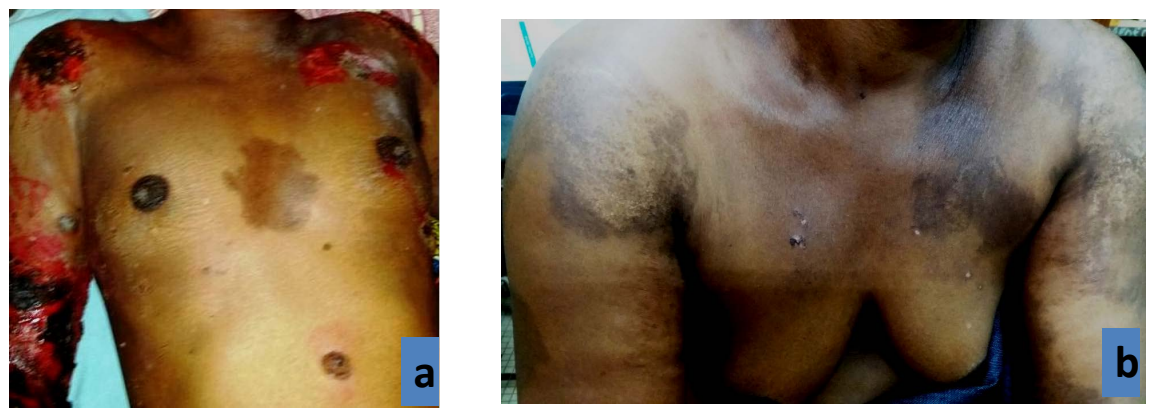

Figure 3. (a) Lesions at the stage of crustous ulcerations near the large folds. we observe on the figure a pigmented macula on the chest, scar of previous episode. (b) After 3 months under corticosteroid and metothrexate we observed cicatrization with pigmented macula. The patient gained weight with corticosteroids. 


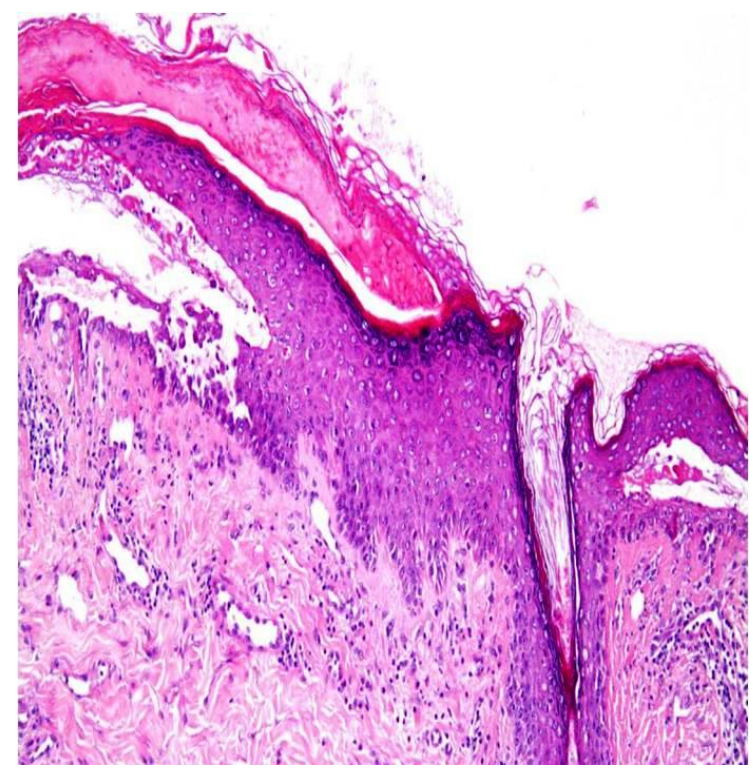

Figure 4. Suprabasal acantholysis with acantholytic cell, hyperacanthosis and papillomatosis.

retrospective study carried out by the Department of Dermatology in Argentina on 203 patients with pemphigus showed that the Hallopeau type accounted for $1.5 \%$ of cases [1]. Its clinical presentation can mislead a practitioner, especially in black people cases. In such a situation, the prognosis of bullous disease may be ignored. The clinical presentation of our case is similar to local signs described in the Hallopeau form. Paronychia frequently appears [4] but were absent in the 2 cases. Mouth ulceration may occur in the form of hilly budding surrounded by fissures [4]. Our cases showed mouth and tong ulcerations. Complications such as deafness, otalgia, otorrhea and facial paralysis are secondarily described [4], though they are absent in our observations. Diagnostic problems on black skin occur with the bullous lichen, the toxicodermatitis, the dermatophytosis, the pemphigus vulgaris, Stevens-Johnson syndrome and eczema. Complementary examinations, especially histology and direct immunofluorescence on surrounding skin through IgG or even C3 make it possible to confirm the strong clinical suspicion [2]. The physiopathology is not well clarified and an association with IEC is described. Many circulating antibodies are in question [5]. Like in our two cases, the treatment is mainly based on oral corticoid therapy at high dose (prednisone $1.5 \mathrm{mg} / \mathrm{kg} /$ day) and on the Lever Protocol, light in case of failure [6] [7].

\section{Conclusion}

$\mathrm{PH}$ is rarely described in our regions. Clinical diagnosis is not obvious for the uninitiated. Our cases are specific because they occur in black people, without classical paronychia and with various responses to the general corticoid therapy. Beyond the clinical presentation, $\mathrm{PH}$ has the same paraclinical diagnosis and the same treatment as PV. 


\section{References}

[1] Pizzariello, G., Olivares, L. and Forero, O., D’Atri, G., Pardal, P.F. and Anaya, J. (2011) Retrospective Study of Hallopeau-Type Pemphigus Vegetans throughout a 20-Year Period. Review of the Literature. Dermatología Argentina, 17, 294-300.

[2] Nelson, CG, Apisarnthanarax, P., Bean, S.F. and Mullins, J.F. (1977) Pemphigus Vegetans of Hallopeau: Immunofluorescent Studies. JAMA Dermatology, 113, 942-945. https://doi.org/10.1001/archderm.1977.01640070076011

[3] Saurat, J.H., Lachapelle, J.M., Lipsker, D. and Thomas, L. (2004) Pemphigus Auto-Immuns. In: Borradori, L., Parmentier, L. and Saurat, J.H., Eds., Dermatologie et infection sexuellement transmissible, 300-301.

[4] Fujimoto, W., Hirano, N., Miyashita, M., Arata, J. and Saito, C. (1991) Pemphigus Vegetans Presenting with Deafness, Otalgia and Facial Nerve Paralysis. British Journal of Dermatology, 6, 609-610. https://doi.org/10.1111/j.1365-2133.1991.tb04961.x

[5] Parodi, H.A.S., Stanley, J.R., Ciaccio, M. and Rebora, A. (1988) Epidermal Antigens in Pemphigus Vegetans. Report of a Box. British Journal of Dermatology, 119, 799-802. https://doi.org/10.1111/j.1365-2133.1988.tb03507.x

[6] Martel, P. and Joly, P. (2001) Pemphigus. The Encycl Med Chir, Dermatology, 98-250-A-10, 28 p.

[7] Benoit Corven, C., Carvalho, P., Prost, C., et al. (2003) Treatment of Pemphigus Vulgaris by Azathioprine and Low Doses of Prednisone (Diagram of Lift). Annales de Dermatologie et de Vénéréologie, 130, 13-15.

Submit or recommend next manuscript to SCIRP and we will provide best service for you:

Accepting pre-submission inquiries through Email, Facebook, LinkedIn, Twitter, etc. A wide selection of journals (inclusive of 9 subjects, more than 200 journals)

Providing 24-hour high-quality service

User-friendly online submission system

Fair and swift peer-review system

Efficient typesetting and proofreading procedure

Display of the result of downloads and visits, as well as the number of cited articles

Maximum dissemination of your research work

Submit your manuscript at: http://papersubmission.scirp.org/

Or contact jcdsa@scirp.org 